\title{
Formação de Professores na Licenciatura em Educação do Campo: diálogos e desafios com Florestan Fernandes ${ }^{1}$
}

Teacher Education in the Rural Education Degree: dialogues and challenges with Florestan Fernandes

Resumo: O presente artigo busca desenvolver uma reflexão acerca da formação de educadores do campo cotejando com elaborações do Patrono da Sociologia Brasileira, conectadas em âmbito educacional e social na dinâmica da luta de classes. Apoiado em elaborações de Florestan Fernandes, e a partir de sua concepção de formação, discutimos ideias fundantes nos processos de formação de educadores, dentre elas o rigor teórico, o vínculo com processos e organizações populares do campo e da cidade e a necessidade do desenvolvimento ético e moral em uma perspectiva de transformação social e individual. Ao final apresenta um conjunto de desafios como parte integrante dos processos de formação de educadores do campo que necessariamente terão que ser encarados nas reflexões da práxis formativa, nas atuações sócio-educacionais e políticas-organizativas.

Palavras-Chaves: Formação de educadores. Educação do campo. Transformação social.

Abstract: This article seeks to develop a reflection about the formation of educators in the field, comatoseing with elaborations of the Patron of Brazilian Sociology, connected in the educational and social context in the dynamics of class struggle. Based on elaborations by Florestan Fernandes, and from its conception of formation, we discuss founding ideas in the processes of training educators, among them the theoretical rigor, the link with popular processes and organizations of the field and the city and the need for ethical and moral development in a perspective of social and individual transformation. At the end it presents a set of challenges as an integral part of the processes of training of educators in the field that will necessarily have to be faced in the reflections of formative praxis, in socio-educational and organizational-policy actions.

Keywords: Formation of educators. Field education. Social transformation.

\section{Introdução}

Como então? Desgarrados da terra? Como assim? Levantados do chão? Como embaixo dos pés uma terra Como a água escorrendo da mão? (Chico Buarque).

\footnotetext{
1 Esse texto é também uma homenagem ao centenário do Patrono da Sociologia brasileira, nascido em São Paulo, no dia 22 de julho de 1920 que faleceu em 10 de agosto de 1995 - Florestan Fernandes.
} 
As linhas que seguem buscam desenvolver reflexões acerca da formação de educadores do campo cotejando com elaborações do educador Florestan Fernandes, destacado pela pesquisadora Duarcides Ferreira Mariosa (2007) o Patrono da Sociologia Brasileira, com ideias conectadas em âmbito educacional e social na dinâmica da luta de classes. Tais reflexões não se esgotam em si mesmas e tão pouco se fecham naquilo que tradicionalmente se trata em Formação de Educadores e em Educação do Campo. Pelo contrário, a intenção é justamente ampliar e aprofundar o horizonte mantendo a materialidade social e educacional que nos constitui enquanto sujeitos sócio-históricos, percebendo que ao mesmo tempo em que construímos a história também somos construídos por ela, o que mantém viva a busca por uma sociedade igualitária.

Vivemos um contexto de instabilidades e crises de dimensões e proporções profundas, internacionalizadas e articuladas simultaneamente entre si: econômica, social, política, ambiental, cultural, de valores, de civilização e na atual conjuntura sanitária, a pandemia enfrentada pelo vírus COVID-19. Podemos pensar que essa crise civilizatória põe em questão o futuro igualitário da humanidade tornando atual a celebre frase de Rosa Luxemburgo pronunciada a pouco mais de um século: "Socialismo ou Barbárie", citada por Martins Fontes (2003).

Tal dilema permanece atual, mesmo que o socialismo não se vislumbre para o amanhã, ele continua no horizonte, como uma das perspectivas da histórica busca por uma nova sociedade, uma sociedade mais justa e com qualidade de vida para a população. Já a barbárie, aqui considerada pelas mazelas enfrentadas pela humanidade, como as desigualdades, penetra de forma avassaladora as relações sociais que se traduzem na destruição e na morte da vida do planeta, na devastação predatória e incalculável dos bens da natureza, no extermínio gritante dos jovens negros e explorados nas periferias das cidades. A humanidade precisa decidir o rumo a seguir, pois, como disse Florestan (1981, p. 34): "Trata-se de saber se o homem será senhor ou escravo da civilização industrial moderna, com todas as perspectivas que ela abre ou para a destruição da humanidade ou para a igualdade e a fraternidade entre 
todos os seres humanos". Nossa aposta vai na direção da igualdade e fraternidade entre todos.

As investidas dos interesses capitalistas imperialistas internacionalizados deixam evidentes as tentativas e possibilidades de cerceamento da liberdade, de repressão ao pensamento e reflexão crítica, de ampliação dos espaços e ações autoritárias e discriminatórias que ainda nos afetam profundamente trazendo à memória sistemas repressores.

$\mathrm{Na}$ atualidade o campo ainda resiste contra as investidas do agronegócio, essa resistência é percebida nos movimentos que lutam por território e dignidade como os Sem Terra, Indígenas, Quilombolas, por exemplo, que ainda precisam do amparo do Estado para a garantia de subsistência em detrimento à dinâmica de desenvolvimento do agronegócio ${ }^{2}$ na agricultura. Por outro lado, os povos do campo resistem e procuram construir alternativas envolvendo a soberania alimentar, a agroecologia, produção de alimentos saudáveis, plantio de árvores, enfim, propondo novas relações com a natureza e entre as pessoas.

Essa condição nos coloca contradições e desafios que necessitam ser enfrentados com firmeza, ousadia, unidade e convicção profunda na capacidade de resistência e luta daqueles que historicamente foram deserdados da terra que buscam superar a situação de exploração. "As contradições não se excluem, elas se interpenetram e é através da luta de classes que elas se resolvem"

\footnotetext{
2 Para Stédile (2013), sinteticamente o agronegócio apresenta as seguintes características: a) organização da produção agrícola na forma de monocultivo em escala de áreas cada vez maiores; b) uso intensivo de máquinas agrícolas, também em escala cada vez mais ampla, expulsando a mão de obra do campo; c) a prática de uma agricultura sem agricultores; d) uso intensivo de venenos agrícolas, os agrotóxicos, que destroem a fertilidade natural dos solos e seus micro-organismos, contaminam as águas dos lençóis freáticos e inclusive a atmosfera, ao adotarem desfolhantes e secantes que evaporam e regressam com as chuvas e, sobretudo, contaminam os alimentos produzidos, trazendo consequências gravíssimas para a saúde da população; e) uso cada vez maior de sementes transgênicas, padronizadas, e agressão ao meio ambiente com técnicas de produção que buscam apenas a maior taxa de lucro em menor tempo (STÉDILE, 2013, p. 33).

Já Fernandes (2013) assim argumenta: "O agronegócio é um novo tipo de latifúndio e ainda mais amplo; agora não concentra e domina apenas a terra, mas também a tecnologia de produção e as políticas de desenvolvimento. A fundação do agronegócio expandiu a conflitualidade, ampliando o controle sobre o território e as relações sociais, agudizando as injustiças sociais" (FERNANDES, 2013, p. 217).

Por sua vez Delgado (2013) explica, "O agronegócio, na acepção brasileira do termo, é uma associação do grande capital agroindustrial com a grande propriedade fundiária. Essa associação realiza uma estratégia econômica de capital financeiro perseguindo o lucro e a renda da terra sob o patrocínio de políticas de Estado" (DELAGADO, 2013, p. 64).
} 
(FERNANDES, 1989, p. 139). Essas lutas acontecem por vez abertas, outras latentes e sutis, mas, estão vivas em diferentes espaços e dimensões da vida social, inclusive nos espaços educacionais. Por isso, ao nosso entender, não há como pensar na formação de educadores do campo fora da dinâmica críticosocial, ou seja, pois é exatamente no entendimento da formação das sociedades que os estudantes podem descobrir que é necessário resistir contra as vulnerabilidades sociais que o capitalismo pode trazer e construir por meio da educação um caminho que supere as exclusões.

As vulnerabilidades sociais dão a impressão que estamos novamente em um circuito fechado, diminuindo e/ou impedindo os avanços, como é o caso do bloqueio da Reforma Agrária, e da destruição de políticas públicas para o campo conquistadas no período anterior; enfraquecimento e esfacelamento de políticas educacionais que atendiam demandas das camadas populares excluídas de uma boa qualidade de vida e vítimas do sistema governamental capitalista como esgotamento e colapso do sistema público de saúde, enfraquecimento de políticas educacionais para o campo, etc. etc.

No entanto, a advertência de Fernandes (1977, p. 5) nos ajuda a pensar ao afirmar que "a história nunca se fecha por si mesma e nunca se fecha para sempre. São homens, em grupos e confrontando-se como classes em conflito, que 'fecham ou abrem' os circuitos da história". Trata-se, portanto, de organizar a rebeldia e canalizá-la, também do ponto de vista da educação, no conjunto das lutas da classe trabalhadora para assim abrir os circuitos da história e avançar na construção de um projeto popular para o Brasil que represente efetivamente rupturas com nosso passado colonial, neocolonial e imperialista e que para tanto há necessidade de levar adiante processos democráticos, nacionais e populares que rompam a fundo e na totalidade esse passado.

Queremos reafirmar essa posição seguindo as palavras de Fernandes (1989), que apesar de outro contexto histórico, permanecem extremamente atuais:

No limiar de uma nova era, o Brasil marcha para o socialismo ou para a fragmentação interna. A pedagogia volta a ser a chave para a decifração do nosso enigma histórico. O que a constituição negou, o Povo realizará. Mas ele não poderá fazê- 
lo sem uma consciência crítica e negadora do passado, combinada a uma consciência crítica e afirmadora do futuro. $\mathrm{E}$ essa consciência, nascida do trabalho produtivo e da luta política dos trabalhadores e dos excluídos, não depende da educação que obedeça apenas à fórmula abstrata da 'educação para um mundo em mudança', mas sim da educação como meio de autoemancipação coletiva dos oprimidos e de conquista do poder pelos trabalhadores (FERNANDES, 1989, p. 10).

Assumimos nesse pequeno ensaio a alternativa de que é possível projetar, lutar e construir uma sociedade nova, em cujo processo de partejamento a educação pode contribuir na formação de sujeitos conscientes, críticos e ativos junto às organizações dos trabalhadores assalariados, camponeses, indígenas, quilombolas, pescadores, trabalhadores semi-livres, etc. É por intermédio de suas lutas negadoras do passado articuladas com uma consciência crítica e afirmadora do futuro que vão se abrindo as veredas por onde passam homens e mulheres em libertação capazes de edificar uma sociedade humanamente emancipada.

Com esse horizonte que aparece como elementos fundantes, propomos uma reflexão acerca da formação de educadores do campo enquanto militantes educadores que cotidianamente em sua práxis, atuam de modo conscientizador e vinculado a processos de organização e lutas populares do/no campo e na cidade, e vinculado aos conteúdos do ensino de modo a relacioná-los ás vivências dos educandos. Assim, a expressão educadores/as não se limita à função dos professores que atuam em sala de aula, mas, refere-se à educadores que desenvolvem atividades pedagógicas-educativas; que assumem funções organizativas nas comunidades, territórios e entidades de classe no âmbito da luta e da organização dos distintos sujeitos do campo em âmbito local e mais geral participam das atividades sociais, nas escolas, nas igrejas, nos centros comunitários, possuem uma ativa e crítica participação social. Enfim, pensamos em um processo de formação que continue a contribuir com o desenvolvimento da consciência analítica dos estudantes e que no seu envolvimento com as contradições da realidade, vinculado aos movimentos populares, consigam coletivamente ir forjando uma consciência crítica, que dentre outras possibilidades, pode assumir como essência o pensamento de Fernandes: "Sem consciência social socialista, não há reforma, nem revolução". Essa condição é 
fundamental para compreender a complexidade do real, se apropriar dele e contribuir com as ações práticas que buscam a sua transformação.

\section{Necessidade da formação teórico-prática com método e rigor}

Compreendendo que os cursos devem estar vinculados às estratégias políticas dos movimentos populares do campo, incluindo a educação protagonizada por esses movimentos, apresentam-se exigências e/ou dimensões que transcendem a formação tradicional, ou seja, que relacione os conteúdos do ensino às realidades dos licenciados de forma dinâmica e criativa. Podemos destacar algumas dessas dimensões: Formação ética primando pela vivência e consolidação de valores e sentimentos humanos que sustentem as escolhas políticas e o vínculo a um projeto coletivo de transformação social; Formação político-ideológica que passa pela apropriação do referencial marxista de análise, por estudos e aprofundamentos teóricos que permitam a compreensão da realidade econômica, cultural, política, social, histórica; Formação baseada na vivência dos princípios organizativos (direção coletiva, planejamento, divisão de tarefas, disciplina, avaliação, etc); No exercício da mística da organização/educação do campo, e de ações que fortaleçam a pertença ideológica à classe trabalhadora e os ideais revolucionários; Formação e/ou construção de habilidades relacionadas à organização, ao método de trabalho de base, de pesquisa da realidade, da pedagogia do exemplo no trabalho com/nas comunidades.

É evidente que essas possibilidades didáticas nem sempre serão atendidas nos cursos e tampouco o serão somente neles. Mas o que buscamos é reafirmar a que os cursos podem contribuir com essa linha formativa, articulando o estudo teórico com atividades/tarefas práticas na dialogicidade complementar entre os Tempos Universidades (TU) e os Tempos Comunidades (TC) durante os quatro anos (ou mais) em que o estudante participa do curso. Torna-se importante potencializar o Tempo Comunidade entendendo-o como tempo/espaço formativo distinto do Tempo Universidade, que ao mesmo tempo integra a totalidade do processo pedagógico do curso e de cada etapa e é maior do que ela, porque diz respeito a uma totalidade mais ampla que é a da vida 
concreta dos educandos/das educandas no seu trabalho, militância no movimento popular, na convivência familiar e comunitária.

Enfatizamos ainda a relevância da pesquisa como uma ferramenta muito importante para a apropriação/construção do conhecimento, ajudando na constituição de uma postura interrogativa e aberta ao estudo e de um pensamento rigoroso, investigativo, tendo em vista uma compreensão mais profunda da realidade e das possibilidades de sua transformação.

Dizendo de outra maneira, a formação de educadores deve primar não apenas pela dimensão técnico-científica (desenvolvimento de habilidades, competências didático-pedagógicas para ser um exímio educador, extremamente importante e necessária), mas, fundamentalmente, encarar as dimensões filosóficas e políticas da formação, pois são elas que nos dão os fundamentos para pensar e produzir uma visão de mundo, de sociedade e de ser humano baseado em pilares de justiça e igualdade. Mais que isso, nos convoca a participar ativamente dos processos de organização e lutas que possam vislumbrar essa nova racionalidade humana, alicerçada nos princípios da igualdade e equidade social.

Bem nos advertiu o arquiteto Oscar Niemeyer quando disse: "Aos jovens não basta sair da faculdade como um ótimo arquiteto, mas, como um homem que leu, que conhece as misérias do mundo e contra elas vai se manifestar", vai lutar! Essa advertência cabe perfeitamente nos fundamentos e princípios da formação de educadores do campo. Ou como disse Florestan Fernandes: "O educador precisa conhecer o mundo, explicar o mundo, transformar o mundo e, para isso, não basta dar ao trabalhador adestramento na situação de trabalho, a escolaridade técnica" (FERNANDES, 1991, p. 49).

Os cursos de formação e a universidade como um todo, segundo Fernandes (1989), devem abrir o horizonte intelectual dos estudantes apresentando conteúdos que tornem a educação um instrumento não só para a vida, mas, para a transformação da vida e da sociedade. Esse horizonte intelectual deve ser crítico, independente/autônomo e engajado, pois como disse Fernandes (1989), não se trata de fazer a cabeça dos estudantes, mas, de inventar e reinventar uma nova racionalidade, uma nova civilização sem 
barbárie. Que educação, que formação os trabalhadores devem ter acesso? Segundo Fernandes (1989, p. 243), "O trabalhador precisa de uma educação que o transforme em alguém capaz de manter uma posição ofensiva nas relações de classe", isto é, tomem consciência da sua função e seu papel na sociedade e atuem como sujeitos capazes de revolucionar e romper com as amarras que os mantém refém e a serviço do capital. É preciso criar "elos" que fortaleçam os mecanismos de libertação possibilitando ao trabalhador uma relação libertária, crítica e revolucionária com a sua situação de existência material, social, educacional e moral.

Assim, a formação dos educadores é um processo não apenas complexo, mas, extremamente difícil, pois, como disse Fernandes (1989), os educadores possuem uma liberdade considerável e, do ponto de vista teórico, podem ser positivistas, conservadores/reformistas marxistas, socialistas, pós-modernos. Podem identificar-se com as classes médias, dominantes ou com as classes exploradas. Ante essa liberdade o educador pode também ter uma ampla margem de atuação política na sociedade, fortalecendo iniciativas/projetos conservadores e/ou críticas e libertadoras. Entendemos que os educadores do campo precisam no campo pedagógico permanecer empreendendo a teoria crítica da educação, fortemente atacada pelo governo atual.

Trata-se portanto, de fazer as críticas à realidade existente e projetar sua superação desde agora e, de acordo com Fernandes (1989) ao se pensar em mudanças, podendo ser de qualquer ordem (econômica, social, educacional, etc.) sempre é mudança política e se o educador acreditar nessas possibilidades, terá que pensar politicamente. É, na mesma dinâmica da luta política, pois,

não podem recuar e se omitir diante das tarefas teóricas e práticas, que eles próprios terão que desvendar, coordenar e converter em fatos concretos, através de sua ação construtiva, inteligente e coletiva. $\mathrm{O}$ avanço silencioso dos que eram antes os condenados da Terra e passaram a ser os perseguidos do sistema abre oportunidades novas para todos. Não podemos ficar indiferentes, aguardando passivamente a decisão dos embates. Temos de avançar com ânimo firme e decidido para libertar a educação e o Brasil das fortalezas do privilégio, do atraso e da opressão (FERNANDES, 1989, p. 19). 
Consideramos um chamamento extremamente atual e vinculado aos nossos processos educativos e formativos no curso de licenciatura; precisamos avançar, abrir novas fronteiras não apenas enquanto direito à educação, mas, enquanto uma educação cujas tarefas teóricas e práticas sejam colocadas em outro patamar na dinâmica das relações de classes na sociedade brasileira. Formamos para transformar e não para reproduzir a ordem estabelecida, desenvolvemos uma pedagogia da desopressão, da libertação dos oprimidos que se dá nos embates cada vez mais radicais e fortes na sociedade.

\section{A formação, sua conexão com a realidade e vínculo político-organizativo com os Movimentos Populares}

Seguindo os trilhos propostos nessa reflexão, concordamos de que os trabalhadores não podem participar ativamente da construção da história, da transformação da sociedade se não é auxiliado a tomar consciência da realidade e da sua capacidade organizativa, coletiva e de lutas para transformá-la. A educação do campo nasce como demanda e proposição dos movimentos populares, das organizações dos camponeses e povos do campo, das águas e das florestas, não apenas enquanto direito (também é), mas, como possibilidades de construir uma nova educação, uma nova escola articulada com um novo projeto de agricultura e de sociedade. Cabe a proposição legada por Fernandes (1995):

Não basta ir à escola. É preciso que o trabalhador tenha meios
de ir além. [...]. O fundamental consiste em desentranhar a
cabeça do trabalhador da subalternização cultural, mental e
ideológica à burguesia, isto é, da alienação social. Pois a
primeira condição a vencer para que o trabalhador deixe de ser
um agente passivo ou defensivo e torne-se um agente
construtivo e ofensivo é extrair dele tudo o que ele tenha de
burguês, desaburguesá-lo para que ele não corra o risco da
cefalização e da cooptação (FERNANDES, 1995, p. 32).

Aqui reside uma questão central na formação de educadores, pois, somos produtos do meio social e herdamos resquícios da velha sociedade que não desparecem automaticamente, nem espontaneamente. Precisamos de processos que articulem a busca de conhecimentos científicos com os aprendizados das lutas e da organização dos camponeses rompendo com os 
parâmetros burgueses ou semi-burgueses que continuam introjetados na consciência e se utilizam dos comportamentos e das atitudes para se manifestarem. A atividade pedagógica aqui proposta, não trata apenas de que os trabalhadores possam adquirir consciência social socialista, mas, de participar ativa e conscientemente das atividades e lutas políticas com aprendizados efetivos na construção de uma nova sociedade.

Os movimentos populares são formas orgânicas que podem evitar, tanto a dispersão das pessoas como das ideias, contribuindo para o desenvolvimento das tarefas que os educandos assumem na dinâmica da sua formação. Há uma dimensão na formação que precisa ser trabalhada, fortalecida e considerada como parte do currículo permitindo que os estudantes passem pela experiência de integrar a organicidade o assumir instâncias de direção, as equipes e núcleos de base fortalecendo o sentimento de pertencimento à coletividade. Diz respeito também aos comportamentos, valores, princípios políticos e organizativos que orientam a práxis dos seus integrantes em todos os níveis. É a organicidade que possibilita o planejamento, a distribuição e acompanhamento do desenvolvimento de tarefas como dimensões pedagógicas que envolvam ativamente os estudantes uma vez que que ninguém se forma profundamente na passividade.

Outra dimensão é a que conecta e articula as experiências, as práticas pedagógicas que se desenvolvem no chão da escola, nas experiências dos movimentos populares com práticas formativas, nesse caso no interior da Universidade. Contudo, a advertência do Mestre nos ajuda a articular dialeticamente esses espaços quando disse que não se faz a revolução dentro da Universidade, a formação universitária e os saberes oportunizados por ela, precisam alcançar os espaços de vivência, as comunidades para que tenham desdobramentos transformadores. "Para atingir esse alvo é preciso lutar simultaneamente dentro e fora dela, pois é na sociedade e, especificamente, na luta de classes que está a matriz da revolução social" (FERNANDES, 1989, p. 212). Essas práticas orientadas pela teoria crítica se voltam para o aprofundamento teórico possibilitando uma nova prática política fortalecendo a luta de classes dos trabalhadores. A formação é esse processo infinito e 
constante de reflexão sobre/na prática, para se apropriar dos conhecimentos já produzidos socialmente; envolve a permanente construção e socialização dos novos conhecimentos que vão sendo gestados graças à vivência da/na realidade concreta; derivam do debate de ideias, do confronto destas com a problemática vivida numa relação de superação coletiva do estágio anterior.

Urge, portanto, formar educadores com um sentimento de pertença à organização, capacidade de indignação e disposição para as lutas de classes, que sintam a necessidade da busca do conhecimento que transcenda o imediato da luta que só é possível com persistência e compromisso com o projeto portador das possibilidades da mudança, o projeto socialista. Concordamos com Fernandes quando diz:

O socialismo continua vivo e o marxismo contém o mesmo significado científico, ideológico e político que sempre teve, seja como meio de descoberta e de difusão da compreensão global dos processos gerais de transformação da civilização existente, seja como organização partidária dos portadores da 'ótica comunista' da autoemancipação coletiva dos trabalhadores e de sua revolução social (FERNANDES, 1995, p. 202).

A história possibilita o entendimento de que governos de ordem burguesa e imperialista estiveram empenhados em esmagar e destruir as tentativas de emancipação da classe trabalhadora. Nesse sentido se torna extremamente atual a advertência do revolucionário Italiano Antônio Gramsci3: "Instrui-vos porque teremos necessidade de toda vossa inteligência. Agitai-vos porque teremos necessidade de todo vosso entusiasmo. Organizai-vos porque teremos necessidade de toda vossa força". Portanto, formação, mobilização e organização são inseparáveis da necessidade da inteligência, do entusiasmo e da força que permitirá levar adiante processos de transformação no âmbito pessoal, educacional, social, na agricultura, rompendo com o instituído pela ordem do capital.

\section{A formação enquanto ação-reflexão, como práxis transformadoras}

3 Palavra de ordem da revista L'Ordine Nuovo, que teve Gramsci entre seus fundadores. 
Reforçamos o aspecto ativo da formação que requer mudanças de atitude perante a vida e a sociedade atual, que possibilite motivar, fortalecer e preparar para os embates teóricos e práticos, na perspectiva de superarmos certas mazelas e desigualdades que herdamos da história. De acordo com o professor Konder,

A práxis é a atividade concreta pela qual os sujeitos humanos se afirmam no mundo, modificando a realidade objetiva e, para poderem alterá-la, transformando-se a si mesmos. É a ação que, para se aprofundar de maneira mais consequente, precisa da reflexão, do autoquestionamento, da teoria; e é a teoria que remete à ação que enfrenta o desafio de verificar seus acertos e desacertos, cotejando-os com a prática (KONDER, 1992, p. 37).

Nesse âmbito da formação, podemos nos interrogar: mas, qual o poder de uma sala de aula? Ou, quais as possibilidades instituintes que ela poderá ter? Buscamos em Florestan uma boa diretriz:

Conferir à sala de aula a capacidade de operar como o experimentum crucis da prática escolar humanizada, de liberação do oprimido, de descolonização das mentes e corações dos professores e alunos, de integração de todos nas correntes críticas de vitalização da comunidade escolar e de transformação do meio social (FERNANDES, 1989, p. 23).

E, continuamos com suas reflexões para reafirmar a necessidade indissociável entre teoria e ação na práxis formativa, assumindo aqui a posição por Ele defendida:

A transformação não é produto do avanço na esfera da consciência e também não é produto de uma elaboração espontânea da realidade. É preciso que a ação prática transformadora se encadeie a uma consciência teórica e prática, que seja, num sentido ou noutro, dentro da ordem ou contra a ordem, revolucionária (FERNANDES, 1989, p. 174).

Esse encadeamento é essencial, profundamente político e nos remete a se vincular à maioria silenciosa dos desgarrados da terra e explorados para a construção de um projeto libertador, sabendo que "É fácil transferir ideias - mas não se pode transferir a transformação do real" (FERNANDES, 1981, p. 73), esta, só é possível por intermédio das forças populares em ação. Acreditamos que se trata de um enorme desafio: contribuir com a formação de sujeitos críticos e capazes de alimentar a esperança na transformação radical das relações e da 
sociedade. E, sabe-se que as transformações são sempre conquistadas a duras penas, nunca são dádivas, sempre vitórias que precisam, quando alcançadas, serem defendidas e aprofundadas, como é o caso da Educação do Campo.

Nesse reencaminhamento a passagem/mudança para o novo, que é uma opção, requer práticas pedagógicas e formativas que visam rupturas, que ampliem e muito os conhecimentos acerca da realidade a ser transformada, pois, como também nos disse Fernandes (1989, p. 167): "Se o educador pensar em mudança, tem que pensar politicamente. Não basta que disponha de uma pitada de sociologia, outra de psicologia, ou de biologia educacional, muitas de didática, para que se torne um agente de mudança". Essa mudança não acontece automaticamente e, tampouco, de um dia para o outro. Ela requer tempo e mecanismos de incentivo e vigilância na sua implementação (prática) cotidiana, daí a necessidade de articular de forma dialética e permanente nossa ação prática com nossa capacidade de reflexão e elaboração teórica, simultaneamente.

Consideramos ainda, que a formação é sempre um processo político, pois, ajuda a preparar forças que se movem vinculadas a uma determinada visão de homem/mulher, de projetos, de sociedade, de futuro. Afinal, as relações entre as classes são um fato político que gera um saber de classe, que demanda uma lucidez indispensável no momento da escolha dos rumos a serem seguidos. Nesse sentido, a formação pretende e pode contribuir para a articulação de forças, na utilização de táticas que buscam a compreensão e a mudança nas formas de com-viver (viver com) e produzir na agricultura e também na sociedade.

Exige que os sujeitos envolvidos na Educação do Campo assumam a construção e implementação do Plano Camponês ${ }^{4}$, da Reforma Agrária Popular $^{5}$, da autonomia e independência dos territórios buscando se contrapor à

\footnotetext{
${ }^{4}$ Para maiores informações acerca do Plano Camponês, ver: MOVIMENTO DOS PEQUENOS AGRICULTORES - MPA. MPA e a resistência camponesa - História, Propostas, Princípios e Organização. Organizar - Produzir - Alimentar. Brasil, 2005.

5 Resumidamente, a partir de sistematizações do próprio MST (2009, p. 18), encontramos aspectos/elementos que a caracteriza como: "Aquela que é feita principalmente pela organização e a luta popular. Ou seja, a força da mobilização e a capacidade de organização dos Sem Terra, apoiados pelas populações locais, permitirão não somente conquistar a terra, mas também buscar condições para o desenvolvimento econômico, social, político e cultural". Compreende-
} 
lógica capitalista de organização da vida, do trabalho e da produção de mercadorias.

\section{A formação como um processo ético e moral}

Articulada com os aspectos anteriores, a formação de educadores, aqui concebidos como militantes educadores, em decorrência do chamado para a educação crítica e libertadora profundamente vinculada à atuação nas comunidades e aos sujeitos do campo, reclama a presença da ética da/na vida e na luta. A ética instiga e fortalece a capacidade de juízo, estabelecendo outras/novas formas/patamares de vida que não relevam/escondem a acomodação, a indiferença, o individualismo exacerbado, a traição, a cooptação, os pactos obscuros para manter/aumentar privilégios/status de qualquer ordem. Enfim uma educação crítica da realidade. Ou seja, uma ética e uma moral que represente os valores, comportamentos e capacidade de juízo numa sociedade igualitária.

Outra questão importante refere-se à coerência (política, ideológica, econômica, moral) entre o discurso e a prática dos militantes/educadores. Os processos de formação podem e devem auxiliar nessa função da vigilância contra os desvios de qualquer ordem, motivando o exercício da coerência política, ideológica, organizativa.

Dessa maneira Fernandes (1989, p. 65) diz o educador movido por critérios éticos: "Precisa se colocar [...] e reconhecer que tem um amplo conjunto de potencialidades, que só poderão ser dinamizadas se ele agir politicamente, se conjugar uma prática pedagógica eficiente a uma ação política da mesma qualidade" (Grifos nossos).

se, portanto, ou fica evidente, que a Reforma Agrária Popular será parte de um amplo processo de mudanças na sociedade brasileira, que necessita alterar a estrutura de organização da produção e da relação do ser humano com a natureza, no sentido da superação da exploração, da dominação política, da alienação cultural e da destruição dos recursos naturais e minerais. Continuando com a proposição, segundo o MST (2006, p. 20-21), os principais objetivos da Reforma Agrária Popular são: "a) Eliminar a pobreza no campo; b) Combater a desigualdade social; c) Garantir trabalho e educação para todos; d) Garantir a soberania alimentar; e) Garantir a participação igualitária de mulheres e homens; f) Preservar a biodiversidade vegetal, animal e cultural; g) Garantir condições de melhoria de vida para todas as pessoas". 
Esses comportamentos referem-se a um conjunto de valores humanistas - dentre esses valores, também concebidos como virtudes - pode-se destacar a solidariedade; a defesa do estudo e do trabalho; a importância da beleza e da vida; o companheirismo e a capacidade de indignação ante as injustiças; a ternura; a coerência, dentre outros. Nessa direção, Fernandes nos motiva com um belo legado, quando diz:

O caráter humano chegou-me por essas frestas, pelas quais descobri que o 'grande homem' não é o que se impõe aos outros de cima para baixo ou através da história; é o homem que estende a mão aos semelhantes e engole a própria amargura para compartilhar a sua condição humana com os outros [...] descobri que a medida do homem não é dada pela ocupação, pela riqueza e pelo saber, mas pelo 'seu caráter' (FERNANDES, 1980a, p. 143-147).

Com essa advertência, nos perguntamos: num mundo conturbado como o que vivemos, em que a violência se naturaliza, a barbárie e o descaso com a vida humana enchem páginas de jornal e espaços televisivos cotidianamente, como os processos de formação podem fortalecer relações de solidariedade, de simplicidade, de caráter, de amor à vida, de coletividade, de sensibilidade e de indignação?

\section{Alguns desafios para (não) concluir}

Os elementos e reflexões aqui propostas, nas linhas e entrelinhas, são passíveis de debates, questionamentos, inclusive discordâncias, uma vez que estamos abertos às críticas com argumento, pois podem perguntar-se: mas, onde está a Educação do Campo? No entanto, é preciso reafirmar e dizer ao que viemos nesse processo de formação de educadores na e para a luta de classes que emerge, se alimenta e impulsiona os movimentos populares que apontam para rupturas e transformações conquistadas com muita luta. Enumeramos alguns desafios para não encerrar a reflexão, o debate e muito menos a práxis emancipatória:

a) Mais do que nunca se torna necessário manter e alimentar a utopia, a esperança na construção de uma nova sociedade. Educandos e educadores precisamos ver a história em processo como possibilidade, de pensar o inédito- 
viável como desafio que nos puxa para frente e não como fatalidade. Nessas situações limites, quando parece não haver alternativas, ali se abrem novas possibilidades, pois, o novo nasce nas entranhas do velho fruto da ação consciente dos sujeitos que não se dão por vencidos;

b) Compreender a formação historicamente constituída da sociedade brasileira na sua essência e interpretar a realidade atual na dinâmica das lutas de classes, utilizando o referencial teórico marxista com todo seu legado, superando os limites ocasionados pela pseudo-concreticidade que fragmenta e superficializa essas análises. A aparência pode ser ponto de partida, mas nunca ponto de chegada, sabendo que esse ponto de chegada se transformará em uma aparência para um novo ponto de partida em outro patamar. Ao mesmo tempo que aparência revela ela esconde a essência e é aqui que reside o busilis da questão: como capturar, compreender, decifrar, a essência a ser transformada? Marx já afirmou que se a aparência fosse igual à essência, não precisaria ciência. Como disse Fernandes (1980a, p. 174): "Os fatos não falam por si mesmos. É preciso interrogá-los e, para isso, é indispensável algum domínio do quadro teórico envolvido". Daí a necessidade de aprofundar nas pesquisas com rigor metódico, qualificar a elaboração teórica expondo a análise profunda e abrangente dessas pesquisas (não basta a descrição, sabendo que ela é importante) tendo como fim último o fortalecimento das causas, das lutas pela emancipação humana;

c) No âmbito educacional e social precisamos construir unidades sólidas que nos fortaleçam para poder transgredir, conspirar, lutar contra inimigos poderosos. Reafirmar no plano da educação do campo a concepção e escola de resistência e alternativa ao agronegócio, ao latifúndio e sobre os rumos da educação dos trabalhadores e, assumir abertamente outra lógica de organizar a vida, o trabalho as relações no campo, rompendo com o nexo da mercadoria ancorada na dinâmica capitalista de produção. Defender a natureza, a biodiversidade, a produção de alimentos saudáveis com práticas efetivas também passam pela educação e pela escola;

d) Se preparar para a manutenção da sociedade democrática, em detrimento às investidas fascistas e autoritárias, homofóbicas, discriminatórias e 
intolerantes. Cuidar da segurança do patrimônio, das ideias, das organizações, das comunidades, dos territórios, das pessoas que ali vivem e trabalham;

e) Formar educadores cultivando e desenvolvendo a capacidade de se reinventar todos os dias, pois, essa reinvenção individual-coletiva mantém vivas e atuais as apostas políticas, as possibilidades que a vida/sociedade permite projetar, para transformá-las, nos transformando. Uma nova sociedade se constrói com homens e mulheres novas, emancipadas, livres - esse desejo pode se efetivar graças à formação crítica e continuada de educadores por meio da atuação das universidades;

f) Lutar contra o fechamento de escolas e, mais que isso, demonstrar pertencimento ao Projeto de Educação do Campo que exige cada vez mais dedicação e entrega engajada e coletiva à invenção de novos caminhos, dando passagem ao novo que germina, com dinamismo e vigor, num contexto de tamanha complexidade, perplexidade e interrogações como o que nos toca viver;

g) Sistematizar, teorizar e socializar as práticas inventivas, inovadoras da educação do campo, se articulando com um projeto de educação emancipadora para o País. A educação de classe é construída com a classe trabalhadora, rompendo com o isolamento para construir força política educacional social, como disse o Mestre: "Contra as ideias da força, a força das ideias".

Até aqui deixamos evidente que se trata de um momento em que alimentamos a esperança e acreditamos nas possibilidades das realizações de antigos/novos projetos, sonhos. Esses períodos difíceis (de crises) são portadores de duas dimensões: uma que busca destruir o que está estabelecido pela ordem e a outra, que busca construir o novo, inventar alternativas outras, nesse caso, uma nova forma de organizar a vida e o trabalho no campo e de uma educação/formação profundamente comprometida e emancipatória. Essas duas dimensões não são sucessivas, mas se entrelaçam o tempo todo, por intermédio das ações, projetos, iniciativas dos diferentes grupos e atores sociais, com os quais também estamos imbricados. $\mathrm{E}$, seguimos com o Professor:

Os grandes problemas da educação não se reduzem a palavras de ordem. São objetivos que nós temos de enfrentar, realidades que temos de transformar, [...] contando com os professores, contando com os estudantes, contando com as famílias dos 
estudantes [...]. Impõem-se gerar uma comunidade de interesses, capaz de galvanizar um processo de mudança educacional e social profundo (FERNANDES, 1989, p. 247).

Esse talvez é o desafio maior: protagonizar rupturas profundas no âmbito educacional e social, sabendo que essas mudanças nunca serão dádivas, mas sim, conquistadas a duras penas; não é um caminho fácil, mas terá que ser aberto por todos aqueles e aquelas que acreditam na utopia socialista. É preciso criar um sentimento das possibilidades dessas rupturas para que estudantes, professores e trabalhadores em geral se empenhem na construção desse movimento real na sociedade.

Por fim, nos acompanha a advertência do Mestre (1980a, p. 252): "Ou o intelectual crítico e militante se empenha no fortalecimento e na difusão do movimento socialista ${ }^{6}$, ou ele voltará a ser um joguete nas mãos das forças culturais de 'conservação da ordem'”. Desse modo, precisamos dizer a que viemos, que educação desejamos, que formação de professores protagonizamos, nos colocando a serviço das diversas categorias de trabalhadores, dos povos do campo e da cidade, para adquiramos a consciência de nós próprios e possamos fortalecer os processos de ruptura com a ordem burguesa - fortalecer os movimentos sócio-educacionais críticos e emancipatórios.

Muitos outros desafios podem ser elencados, mas o aqui explicitado já está de bom tamanho. A decisão de enfrentá-los do ponto de vista teórico e prático para buscar avançar superando-os, depende de cada um de nós e coletivamente. Façamos a nossa parte e teremos a história como recompensa!

6 Encaro o movimento de uma perspectiva mais ampla, uma confluência de forças anticapitalistas. Dentro de uma sociedade capitalista surgem forças antagônicas ao capitalismo, que buscam acabar com o modo de produção capitalista, o regime de classes, o Estado nacional, o sistema de poder da burguesia. E esse movimento tanto pode assumir uma forma gradualista quanto uma forma revolucionária. Então, o movimento é uma confluência das forças, de todas as forças que se voltam contra a ordem existente. Ou para introduzir reformas antiburguesas dentro dessa ordem; ou para alimentar uma revolução contra a ordem e organizar a sociedade, a economia, o sistema de poder em novas bases (FERNANDES, 1980b, p. 05). 


\section{Referências}

DELGADO, Guilherme et.al. Avaliação do programa de aquisição de alimentos da agricultura familiar. Brasília, 2005. Disponível em: <www.ipea.gov.br/pub/td/2005/td_1145.pdf >. Acesso em 05 de maio de 2017.

FERNANDES, Florestan. Circuito fechado: quatro ensaios sobre o "poder institucional". São Paulo: Hucitec, 1977.

FERNANDES, Florestan. A sociologia no Brasil. Petrópolis: Vozes, 1980a.

FERNANDES, Florestan. Movimento socialista e partidos políticos. São Paulo: Hucitec, 1980b.

FERNANDES, Florestan. Pode e contrapoder na América Latina. Rio de Janeiro: Zahar Editores S.A., 1981.

FERREIRA. Mariosa, Duarcides. M338f Florestan Fernandes e a sociologia como crítica dos processos sociais / Duarcides Ferreira Mariosa. - Campinas, SP: [s. n.], 2007. Orientador: Josué Pereira da Silva. Tese (doutorado) Universidade Estadual de Campinas, Instituto de Filosofia e Ciências Humanas.

FERNANDES, Florestan. O dilema educacional. São Paulo: Cortez: Autores Associados, 1989.

FERNANDES, Florestan. Em busca do socialismo: últimos escritos \& outros textos. São Paulo: Xamã, 1995.

FERNANDES, Bernardo Mançano. Questão agrária: conflitualidade e desenvolvimento territorial. In: STÉDILE, João Pedro (Org.). A questão agrária no Brasil: o debate na década de 2000. São Paulo: Expressão Popular, 2013.

KONDER, Leandro. O futuro da filosofia da práxis: o pensamento de Marx no século XXI. São Paulo: Paz e Terra, 1992.

LUKÁCS, Georg "Rosa Luxemburg, marxiste", em Histoire et conscience de classe (Paris, Minuit, 1960), p. 65. [Ed. bras.: História e consciência de classe, São Paulo, Martins Fontes, 2003.]

MOVIMENTO DOS TRABALHADORES RURAIS SEM TERRA. A Reforma Agrária necessária: por um projeto popular para a agricultura brasileira. São Paulo: MST, 2006.

MOVIMENTO DOS TRABALHADORES RURAIS SEM TERRA. Os desafios da luta pela Reforma Agrária Popular e do MST no atual contexto. São Paulo: MST, 2009. (Caderno de Debates n. 1).

STÉDILE, João Pedro, (Org.). A questão agrária no Brasil: o debate na década de 2000. v. 7. São Paulo: Expressão Popular, 2013. 
Sobre os Autores

Adelar João Pizetta

Professor na Universidade Federal do Espírito Sando, DECH/CEUNES/UFES

Marília Alves Chaves Silveira

Doutoranda em História Social das Relações Políticas - Universidade Federal do Espírito Santo 